\title{
Large-strain consolidation modeling of mine waste tailings
}

\author{
Maki Ito and Shahid Azam*
}

\begin{abstract}
Background: Sustainable management of mine waste tailings during operation, closure, and reclamation requires a clear understanding of modeling the large-strain consolidation behaviour of these loose and toxic slurries. A state-of-the-art was presented focusing on process phenomenology and coordinate systems for tailings dewatering thereby devising a simple constitutive equation with a small number of input parameters. A one-dimensional self-weight consolidation model for quiescent conditions was developed using the finite element method. Test data on oil sand fine tailings were used for model training and predictions were made for an upper bound and a lower bound of various tailings types using a $1 \mathrm{~m}$ high hypothetical column.

Results: Results indicated that hydraulic conductivity along with specific gravity dictated pore water pressure dissipation and effective stress development with respect to both time and depth. Likewise, volume compressibility and initial solids was found to govern the void ratio reduction and solids content increase with respect to both time and depth.

Conclusions: The developed model requires a small numbers of input parameters and is capable of capturing the behaviour of a wide range of tailings. Depending on field conditions, the model can predict multiple filling conditions and various types of drainage systems in tailings containment facilities by incorporating appropriate boundary conditions.
\end{abstract}

Keywords: Large-strain consolidation; Mine waste tailings; Numerical modeling

\section{Background}

Large volumes of mine tailings (solid minerals suspended in chemical-rich liquids) are generated worldwide as by-products of ore beneficiation. Conventionally, these loose slurries are deposited on ground with perimeter dykes constructed from their relatively coarser fraction. Such facilities are notorious for a high failure rate and the resulting economic, social, health, and environmental issues (Azam and $\mathrm{Li}, 2010$ ). To reduce tailings footprint, next-generation containment strategies include waste disposal in mined-out pits or in thickening vessels. The storage capacity of these facilities depends on the dewatering behaviour of the deposited material under self weight. The settling process (rate and amount) is influenced by complex physicochemical phenomena at solid-liquid interfaces. Whereas field monitoring and laboratory testing are

\footnotetext{
* Correspondence: Shahid.Azam@URegina.CA

Environmental Systems Engineering, Faculty of Engineering and Applied

Science, University of Regina, 3737 Wascana Parkway, Regina SK, S4S OA2,
} Canada routinely carried out to understand the consolidation behaviour of the placed tailings, these methods are quite expensive, time consuming, and material specific. Sustainable waste management during operation, closure, and reclamation requires a general understanding of tailings consolidation.

The numerical prediction of large-strain consolidation properties of slurries has evolved over the years. Non-linear consolidation equations were independently formulated by Mikasa (1965) and Gibson et al. (1967) and were subsequently modified by Koppla (1970) and Somogyi (1980) to facilitate mathematical solution. Various deposition conditions such as quiescent, staged filling, surcharge loading, and initial solids content were analyzed by Townsend and McVay (1990) and Priestley (2011). Likewise, different forms of the constitutive relationships were employed (Caldwell et al., 1984; Jeeravipoolvarn et al., 2009a) and consolidation models were extended to include sedimentation (Azam et al., 2009; Jeeravipoolvarn et al., 2009b). The main problems with such models are the large number of

\section{包 Springer}


input parameters and the complexity in solving the constitutive equations. Furthermore, most of the models were developed for material specific consolidation properties and a general purpose large-strain model is currently non-existent (Bartholomeeusen et al., 2002; Priestley et al., 2011).

The main objective of this paper was to study the large-strain consolidation modeling of mine waste tailings. Initially, a stat-of-the-art was established focusing on process phenomenology and coordinate systems for tailings dewatering thereby devising a simple constitutive equation with a small number of input parameters. Next, a one-dimensional self-weight consolidation model was developed for quiescent conditions because of negligible lateral drainage, absence of surcharge loading, and diminishing effect of filling on underlying sediments in the containment facilities. Finite element analysis was chosen for model development because of its robustness in capturing the changes in material coordinates during large strain tailings consolidation. The model was applied to capture the behaviour of a wide range of tailings using the tailings classification scheme of Paul and Azam (2013) that captures physicochemical interactions arising from ore geology and mill processing. Finally, test data on oil sand fine tailings were used for model calibration and predictions were made for an upper bound and a lower bound of various tailings types using a $1 \mathrm{~m}$ high hypothetical column.

\section{State of the art}

Figure 1 describes the settling phenomenon of a slurry. The self-weight settling versus the elapsed time plot (Figure 1a) for a deposited tailings consists of sedimentation and consolidation. Initially, the slurry settles with a rapid decrease in the interface height from point 'A' through ' $\mathrm{B}$ '. This hindered sedimentation refers to the settling of a spatial network of soil particles without measurable effective stress (McRoberts and Nixon, 1976). Simultaneously, a sediment starts to form at the bottom (point ' $C$ ') and grows over time following a sediment formation line that eventually meets with the solid-liquid interface at point ' $\mathrm{B}$ '. The sediment undergoes consolidation as the solid grains are in contact and transmit effective stresses (Terzaghi et al., 1996). Subsequent deformation between point ' $\mathrm{B}$ ' and point ' $\mathrm{D}$ ' is attributed to the expulsion of pore pressure. The boundary between sedimentation and consolidation is not fixed and is governed by the inherent properties of the slurry. Additional deposition results in similar plots for each layer. Overall, all of these interface height versus time plots can be summarized in constitutive relationships for volume compressibility $\left(e-\sigma^{\prime}\right)$ and hydraulic conductivity $(k-e)$, as shown in Figure $1 \mathrm{~b}$ and $1 c$, respectively. These relationships explain the void ratio (e) decrease with an increase in effective stress $\left(\sigma^{\prime}\right)$ along with a corresponding decrease in hydraulic conductivity $(k)$.

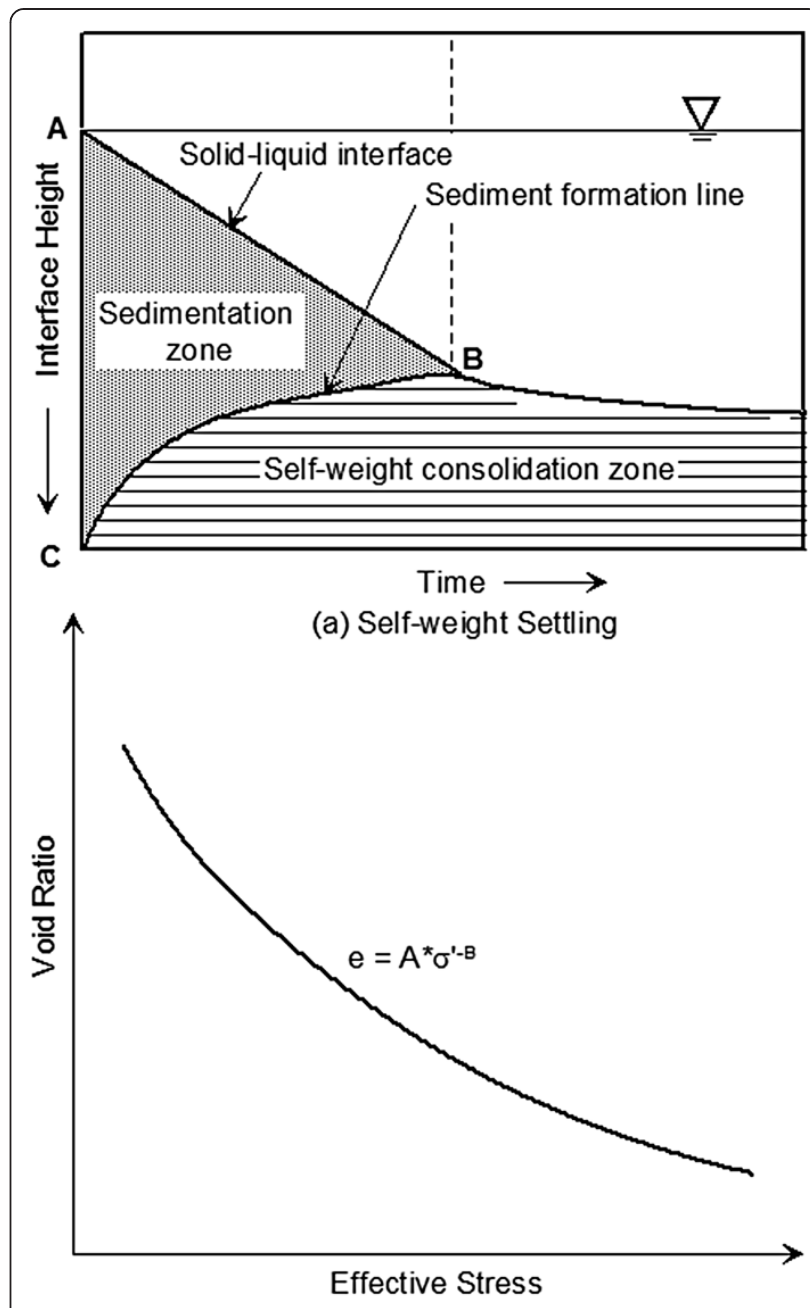

(b) Volume Compressibility

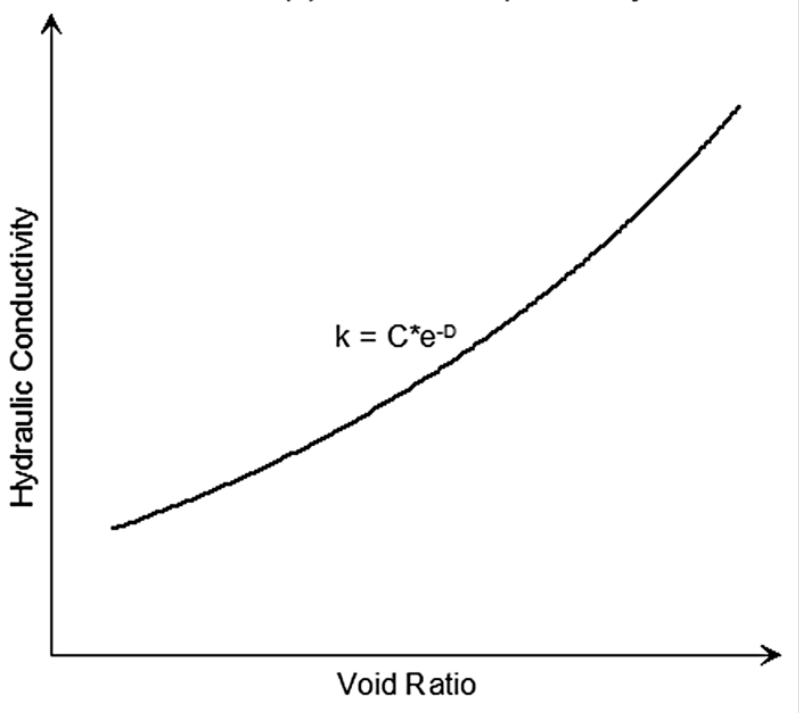

(c) Hydraulic Conductivity

Figure 1 Schematic of large-strain consolidation phenomenon: (a) self-weight settling; (b) volume compressibility; and (c) hydraulic conductivity. 


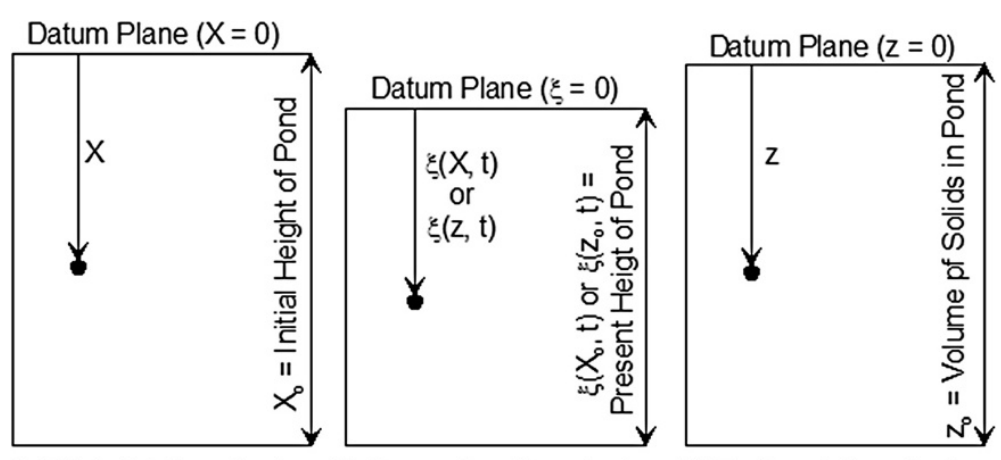

(a) Material Coordinates (b) Convective Coordinates (c) Reduced Coordinates

Figure 2 Schematic of coordinate systems for large-strain consolidation modeling: (a) material coordinates; (b) convective coordinates; and (c) reduced coordinates.

Generally, these relationships are best described using power law functions and the fit parameters (A, B, C, D) are used for numerical modeling.

Denoting time by $t$, depth with respect to datum by $x$, excess pore water pressure by $u$, and coefficient of consolidation by $C_{v}$, the governing equation for infinitesimal deformation in clays can be written as follows (Terzaghi et al., 1996):

$$
\frac{\partial u}{\partial t}=C_{v} \frac{\partial^{2} u}{\partial x^{2}}
$$

This theory assumes a linear stress-strain relationship, a constant hydraulic conductivity, and infinitesimal strain. The low compressibility of clays allows the use of Eulerian reference frame in which material deformation is related to a fixed plane in space. Because of significant volume changes, the use of Eulerian coordinate system (in which flux rate and soil movement are measured with respect to a fixed reference plane) is not valid for tailings consolidation.

Figure 2 describes the coordinate systems pertinent to tailings consolidation. The material coordinate system

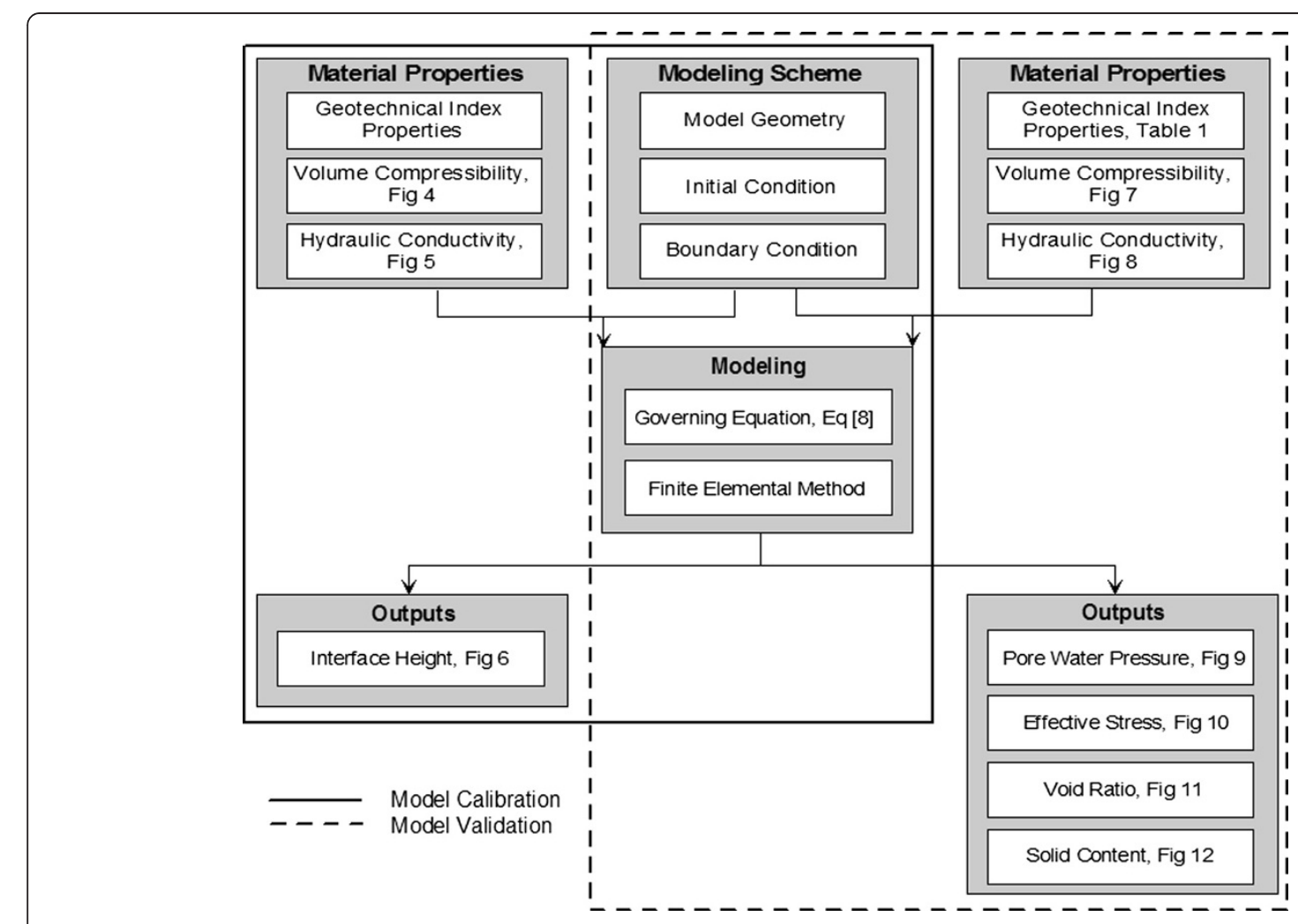

Figure 3 Flow chart of numerical modeling for large-strain consolidation. 


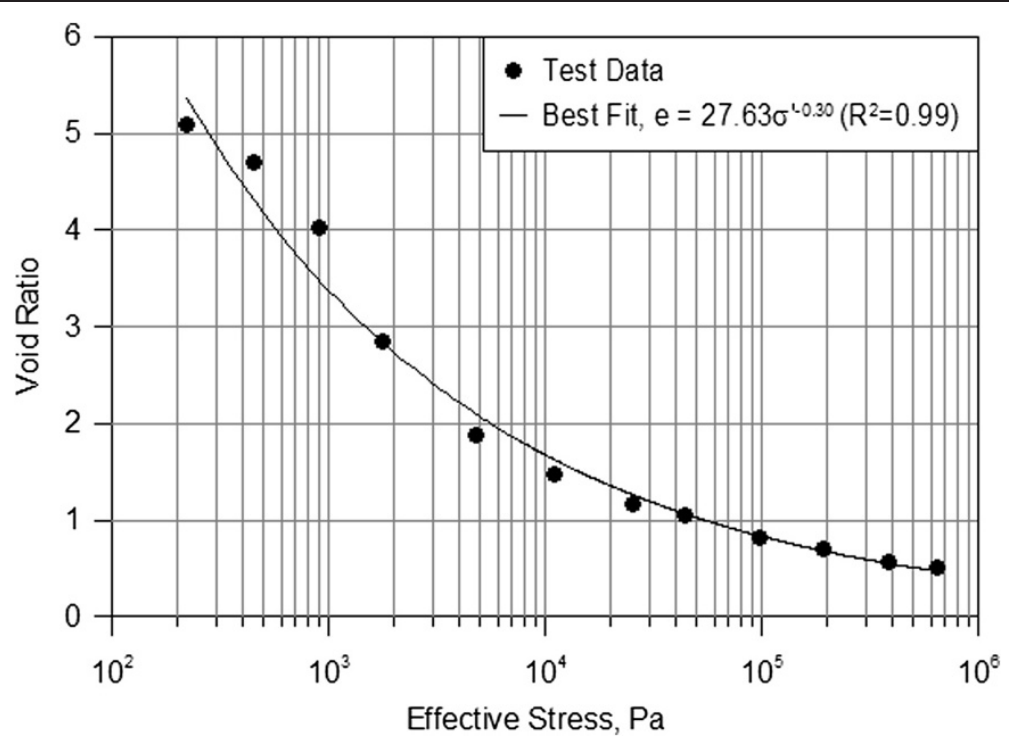

Figure 4 Volume compressibility relationship for oil sand fine tailings.

(Figure 2a) focuses on a particle that occupies position $X$ from a datum $(X=0)$ located at the tailings upper surface at time $t=0$. The datum $(\xi=0)$ shifts downward during consolidation such that the particle's new position ( $\xi$ at time, $t$ ) can be represented by the convective coordinate system (Figure $2 \mathrm{~b}$ ). This system focuses on the space occupied by the particle instead of on the particle itself. To solve the governing equation (written in the material coordinate system), the geometry needs to be updated for each time step thereby increasing the computation time. The reduced coordinate system (Figure 2c) focuses on the solid volume $(z)$ occupied between the fixed datum $(z=0)$ and the point of interest at time, $t$. It simplifies numerical implementation because this system does not require updated geometry at each time step. The datum settlement can be obtained by converting the solution of the reduced coordinate system to the appropriate coordinate system, that is, material coordinate system for $t=0$ and convective coordinate system for $t>0$. The coordinate transformation among the three systems uses the following conversions (McNabb, 1960):

$$
\frac{\partial X}{\partial \xi}=\frac{1+e_{o}}{1+e}
$$

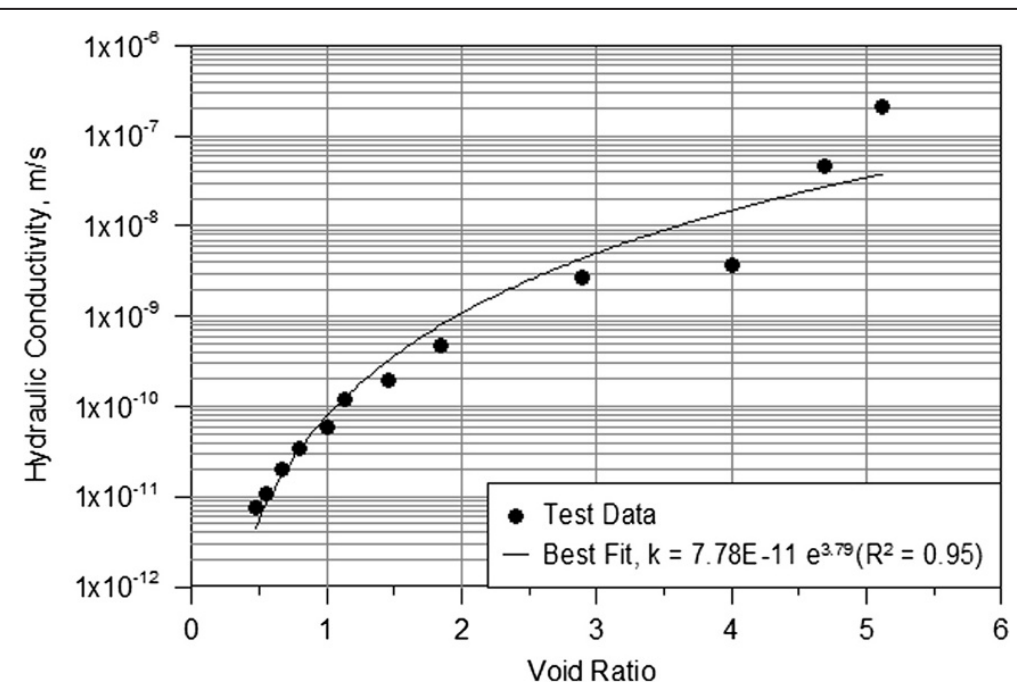

Figure 5 Hydraulic conductivity relationship for oil sand fine tailings. 


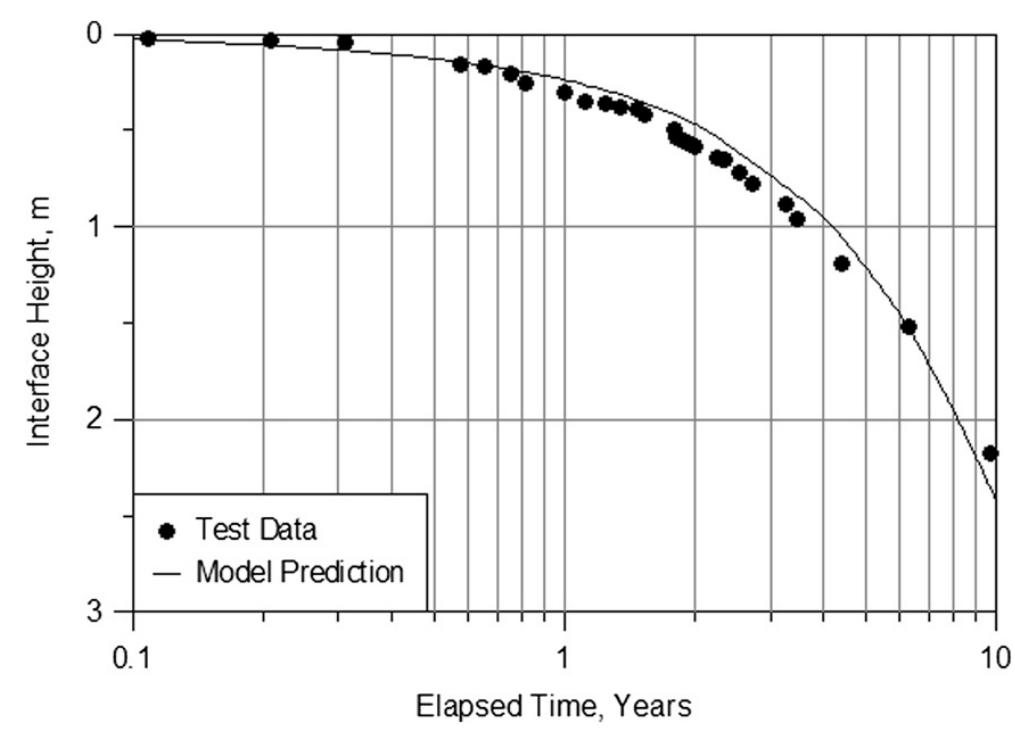

Figure 6 Model training results in terms of interface settlement versus elapsed time.

$$
\begin{aligned}
& \frac{\partial z}{\partial X}=\frac{1}{1+e_{o}} \\
& \frac{\partial \xi}{\partial z}=1+e
\end{aligned}
$$

The reduced coordinate system in the consolidation theory allows for the formulation of a governing equation with inherent large deformations due to the self-weight of materials. Using vertical equilibrium, continuity balance, and a fluid flow relationship, Gibson et al. (1967) developed the following equation for one dimensional largestrain consolidation:

$$
\pm\left(\frac{\gamma_{s}}{\gamma_{f}}-1\right) \frac{d}{d e}\left[\frac{k}{1+e}\right] \frac{\partial e}{\partial z}+\frac{\partial}{\partial Z}\left[\frac{k}{1+e} \frac{d \sigma^{\prime} \partial e}{d e \partial z}\right]+\frac{\partial e}{\partial t}=0
$$

Koppla (1970) formulated the following equation by rearranging continuity and flow:

$$
\frac{\partial}{\partial z}+\left[-\frac{k}{\gamma_{w}(1+e)} \frac{\partial u}{\partial z}\right]+\frac{d e}{d \sigma^{\prime}} \frac{\partial \sigma^{\prime}}{\partial t}=0
$$

Denoting specific gravity of the solids by $G_{s}$ and the coordinate difference between the surface and the point in question by $\Delta z$, Somogyi (1980) updated the above equation using the following time dependent effective stress:

$$
\frac{\partial \sigma^{\prime}}{\partial t}=\left(G_{s}-1\right) \gamma_{f} \frac{d(\Delta z)}{d t}-\frac{\partial u}{\partial t}
$$

Combining equations 6 and 7 leads to a governing equation in terms of excess pore pressure:

\begin{tabular}{|c|c|c|c|c|c|c|}
\hline Slurry type & $G_{s}$ & $\begin{array}{l}w_{L} \\
(\%)\end{array}$ & $\begin{array}{l}W_{P} \\
(\%)\end{array}$ & $\begin{array}{l}I_{P} \\
(\%)\end{array}$ & $\begin{array}{l}\text { USCS } \\
\text { Symbol }\end{array}$ & Reference \\
\hline \multicolumn{7}{|c|}{ (a) Sedimentary clays } \\
\hline China clay & 2.66 & 53 & 32 & 21 & $\mathrm{MH}$ & $\begin{array}{l}\text { Znidarcic } \\
\text { et al., } 1986\end{array}$ \\
\hline Georgia Kaolin & 2.6 & 44 & 25 & 19 & $\mathrm{CL}$ & $\begin{array}{l}\text { Znidarcic } \\
\text { et al., } 1986\end{array}$ \\
\hline Phosphate Slime & 2.77 & 100 & 40 & 60 & $\mathrm{CH}$ & Roma, 1976 \\
\hline \multicolumn{7}{|l|}{ (b) Residual soils } \\
\hline Laterite & 3.16 & 83 & 42 & 41 & $\mathrm{MH}$ & Azam et al., 2009 \\
\hline Bauxite & 3.05 & 54 & 40 & 14 & $\mathrm{MH}$ & Cooling,1985 \\
\hline Uranium & 2.81 & 32 & 27 & 5 & $\mathrm{ML}$ & Matyas et al., 1984 \\
\hline \multicolumn{7}{|l|}{ (c) Oil sand tailings } \\
\hline Ore A-C, RPW & 2.55 & 50 & 26 & 24 & $\mathrm{CH}$ & Miller et al., 2010 \\
\hline Ore A-NC, TRW & 2.51 & 60 & 31 & 29 & $\mathrm{CH}$ & Miller et al., 2010 \\
\hline Ore B-C, RPW & 2.48 & 52 & 27 & 25 & $\mathrm{CH}$ & Miller et al., 2010 \\
\hline Ore B-NC, TRW & 2.45 & 58 & 28 & 30 & $\mathrm{CH}$ & Miller et al., 2010 \\
\hline Ore A-NC, URW & 2.5 & 55 & 28 & 27 & $\mathrm{CH}$ & Miller et al., 2010 \\
\hline Desanded & 2.65 & 57 & 25 & 32 & $\mathrm{CH}$ & Lord and Liu, 1998 \\
\hline Cyclone overflow & 2.53 & 50 & 21 & 29 & $\mathrm{CH}$ & $\begin{array}{l}\text { Jeeravipoolvarn } \\
\text { et al., 2009a }\end{array}$ \\
\hline
\end{tabular}

$$
\frac{\partial}{\partial z}\left[-\frac{k}{\gamma_{f}(1+e)} \frac{\partial u}{\partial z}\right]+\frac{d e}{d \sigma^{\prime}}\left[\left(G_{s}-1\right) \gamma_{f} \frac{d(\Delta \mathrm{z})}{d t}-\frac{\partial u}{\partial t}\right]=0
$$

Table 1 Geotechnical index properties of selected fine-grained tailings

Extraction Process: $C$, caustic; $N C$, non-caustic.

Pore Water: $R P W$, recycled pond water; $T R W$, treated river water; URW, untreated river water. 

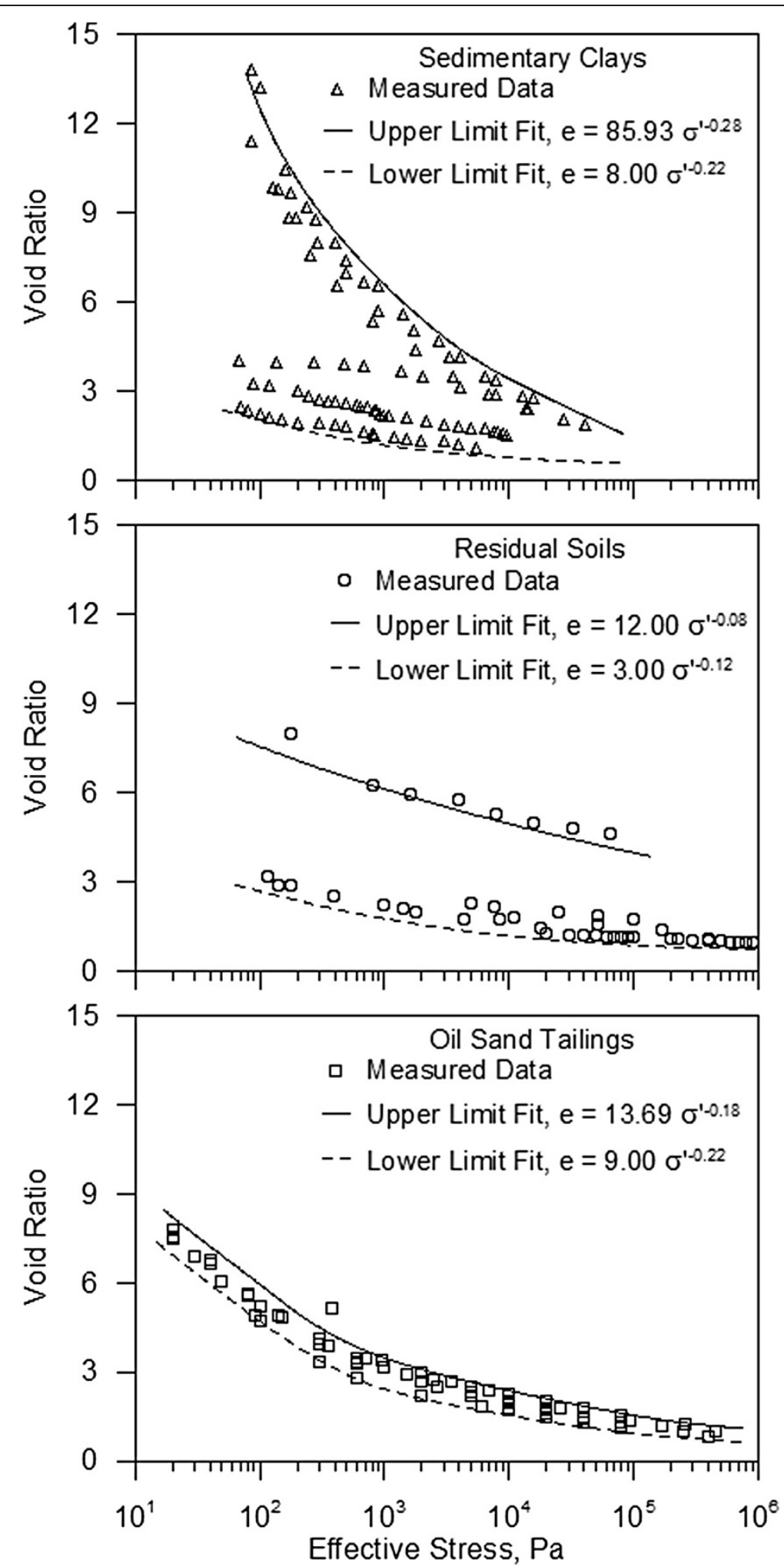

Figure 7 Volume compressibility relationships for various types of tailings. 


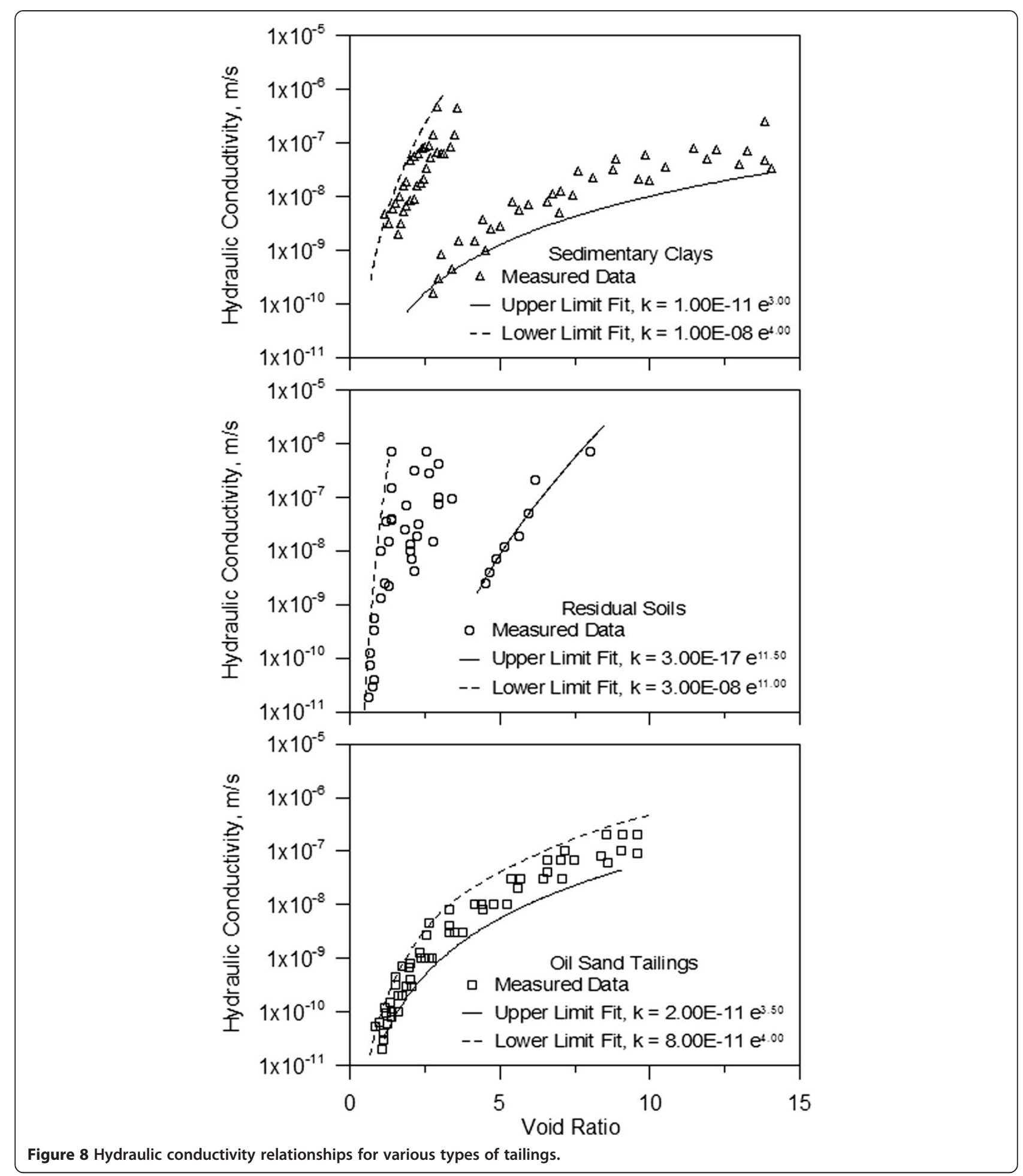

\section{Model development}

Figure 3 describes the large-strain consolidation modeling process. Tailings contained in a column with no horizontal discharge and homogeneous material properties provided the rationale to develop a one-dimensional model. The model required four input parameters related to tailings properties, namely: volume compressibility (A and B), hydraulic conductivity (C and D), initial solids content, and specific gravity. The constitutive relationships were obtained from published large-strain consolidation data. 
The model geometry consisted of a vertical tailings column (10 m high for model training and $1 \mathrm{~m}$ high for model validation) with no drainage at the bottom and dewatering in the upward direction. Quiescent conditions were simulated using 10 years for model training and 1 year for model validation. The governing equation 8 was solved in terms of pore water pressure by using a general partial differential equation solver FlexPDE. The solver utilized the finite elemental method generating a triangular mesh over a quasi-two dimensional geometry. Finite element analysis was chosen because of its robustness in capturing the changes in material coordinates during large-strain tailings consolidation. The adequacy of the mesh was constantly calculated and the automatic mesh refinement feature of the solver was applied to reduce error to a tolerance of (0.001). Using the script editing facility, the governing equation and material properties were directly put in the model compiler. An equation analyzer expanded the defined equation and the material properties, performed spatial differentiation, and applied integration by parts thereby reducing second order terms to create symbolic Galerkin equations for use in the weighted residual method. The Galerkin equations were further differentiated to form the Jacobian coupling matrix for improved convergence. Likewise, the solution curvature was also calculated to include time integration for better accuracy. The model outputs were in the form of pore water pressure, effective stress, void ratio, and solid content profiles.

\section{Results and discussion}

The model was trained using published data of oil sand fine tailings $\left(G_{s}=2.28\right.$; initial solids content of $\left.31 \%\right)$ in a $10 \mathrm{~m}$ standpipe. Figures 4 and 5 give the volume compressibility and the hydraulic conductivity relationships for the investigated tailings. Power law fits were applied

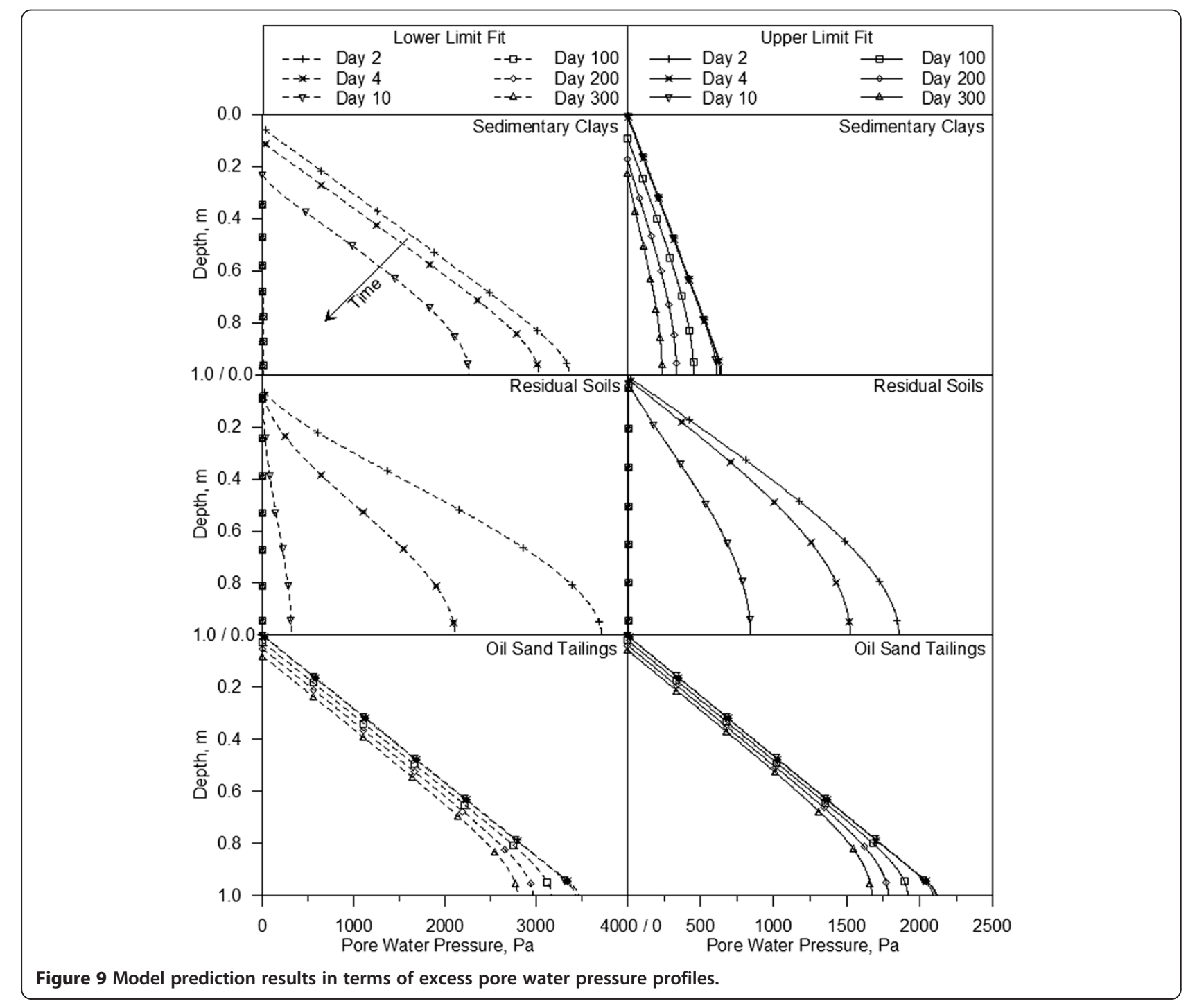


to handle the nonlinearity in both relationships. A detailed description of material behaviour was provided by Jeervipoolvarn et al. (2009a).

Figure 6 compares the modeling results with the measured data from Jeeravipoolvarn et al. (2009a) in the form of interface height plotted over 10 years. The modeling results closely approximated the measured data over the entire time. The relatively lower measured values after about 9 months are attributed to an increased possibility for evaporation and leakage from the standpipe and external disturbances due to natural and anthropogenic activity.

The model was validated to determine the effectiveness of capturing the consolidation behaviour of various tailings. Table 1 gives the geotechnical index properties of selected fine-grained slurries. The slurries were classified into sedimentary clays, residual soils and oil sand tailings based on their geological origin and mining operation. The specific gravity $\left(G_{s}\right)$ of sedimentary clays ranged from 2.6 to 2.77 , which is the typical range for such materials (Wesley, 2010). Conversely, residual soils showed higher $G_{s}$ values due to the presence of ferrous minerals such as goethite and hematite in laterite (Azam, 2005), and gibbsite and hematite in bauxite (Newson et al., 2006); the higher $G_{s}$ (in comparison with sedimentary clays) of uranium tailings was attributed to the high amount of muscovite (Paul and Azam, 2013). The low $G_{s}$ $(2.55 \pm 0.1)$ for oil sand tailings was due to the presence of bitumen $\left(G_{b}=1.03\right)$ with variations attributable to the variable amount of bitumen in the different samples (Miller et al., 2010). The consistency limits varied over a wide range due to the presence of different types and amounts of clay minerals. Although the consistency limits are influenced greatly by the type of process

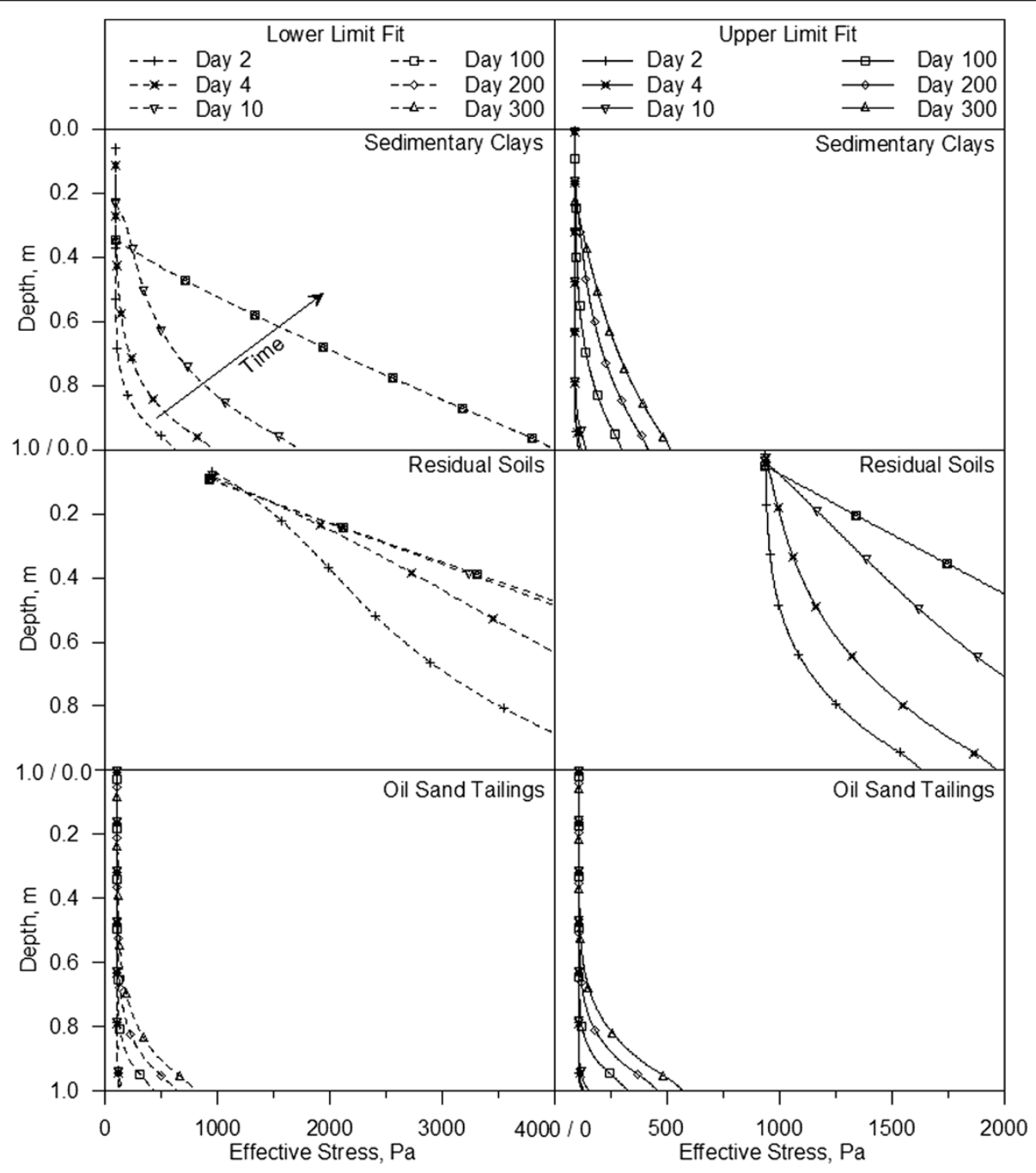

Figure 10 Model prediction results in terms of effective stress profiles. 
water, data on the chemical composition of water was not readily available.

Figure 7 plots void ratio versus effective stress data for various types of tailings. Whereas all materials exhibited a decreasing trend, each material group had significant variations in void ratio especially at low effective stresses. Therefore, an upper limit and a lower limit were used to cover the entire range of material properties within each group. Power law equations were found to best describe the volume compressibility behaviour of the investigated tailings.

Figure 8 gives void ratio versus hydraulic conductivity data for various types of tailings. All materials followed an increasing power law function and showed large variations in hydraulic conductivity at high void ratios. Once again, the upper and lower limits (corresponding to those in Figure 7) were used to capture the wide range of hydraulic conductivity for each material group.
Figures 9 and 10 presents the pore water pressure and the effective stress profiles for a $1 \mathrm{~m}$ high column. In the first plot, the progress of self-weight consolidation is observed by the gradual increase in the vertical component of the curves that tend to reach the ordinate. Conversely, the same phenomenon is represented by a diminishing nonlinearity in the latter plot. Overall, the lower limit predictions showed better pore water dissipation and effective stress development compared to the upper limit predictions because of low volume compressibility (Figure 7) and high hydraulic conductivity (Figure 8 ) in the former case. The lower limit of the sedimentary clays and all of the residual soils completed self-weight consolidation within 300 days. On the contrary, the upper limit of the sedimentary clays and all of the oil sands fine tailings were found to be undergoing consolidation up to that time. Overall, results indicated that hydraulic conductivity (Figure 8)

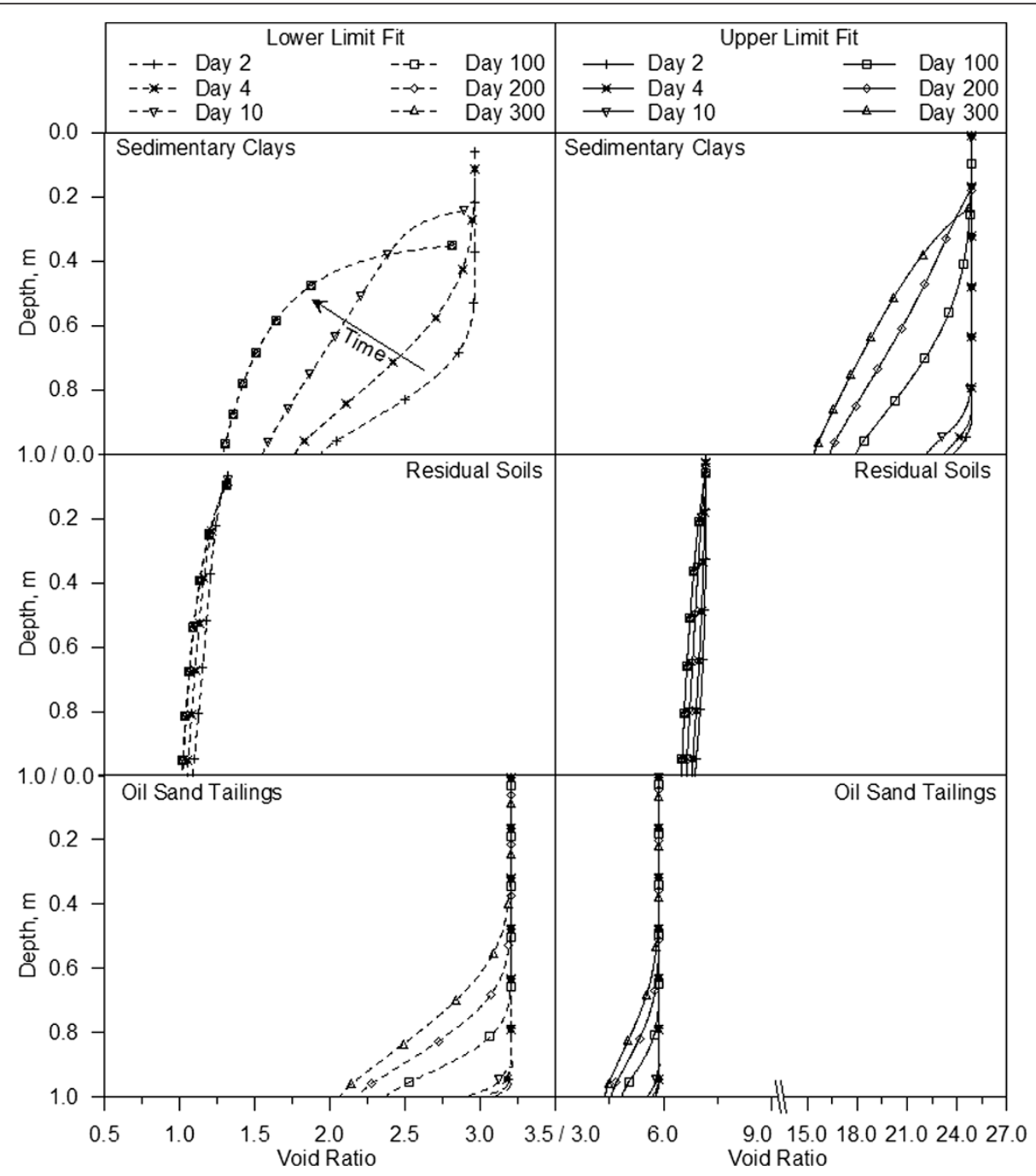

Figure 11 Model prediction results in terms of void ratio profiles. 
along with specific gravity (Table 1 ) dictated the rate of consolidation with respect to both time and depth, as evident from pore water pressure dissipation (Figure 9), and effective stress development (Figure 10).

Figures 11 and 12 shows the void ratio and the solid content profiles for a $1 \mathrm{~m}$ high column. In both plots, the progress of self weight consolidation is observed through the curve shape that changes from concave to convex over time. Generally, the predictions with lower limit fits showed better void ratio reduction and solids content increase compared to the upper limit predictions due to the afore-mentioned reasons. Similar to Figures 9 and 10, the lower limit of the sedimentary clays and all of the residual soils finished self weight consolidation within 300 days. Conversely, the upper limit of the sedimentary clays and the entire oil sand fine tailings continued to undergo consolidation during that time. Overall, volume compressibility (Figure 7) and initial solids was found to govern the amount of consolidation with respect to both time and depth, as given by void ratio reduction (Figure 11) and solids content increase (Figure 12).

\section{Conclusions}

A one-dimensional self weight consolidation model for quiescent conditions was developed in a finite element code. The model was calibrated using oil sand fine tailings and validated through a wide range of tailings. The one dimensional model captured the dewatering behaviour because of the homogeneous nature of fine grained tailings. The developed model requires a small numbers of input parameters and capable of capturing the behaviour of a wide range of tailings. Depending on field conditions, the model can predict multiple filling conditions and various types of drainage systems in tailings containment facilities by incorporating appropriate boundary

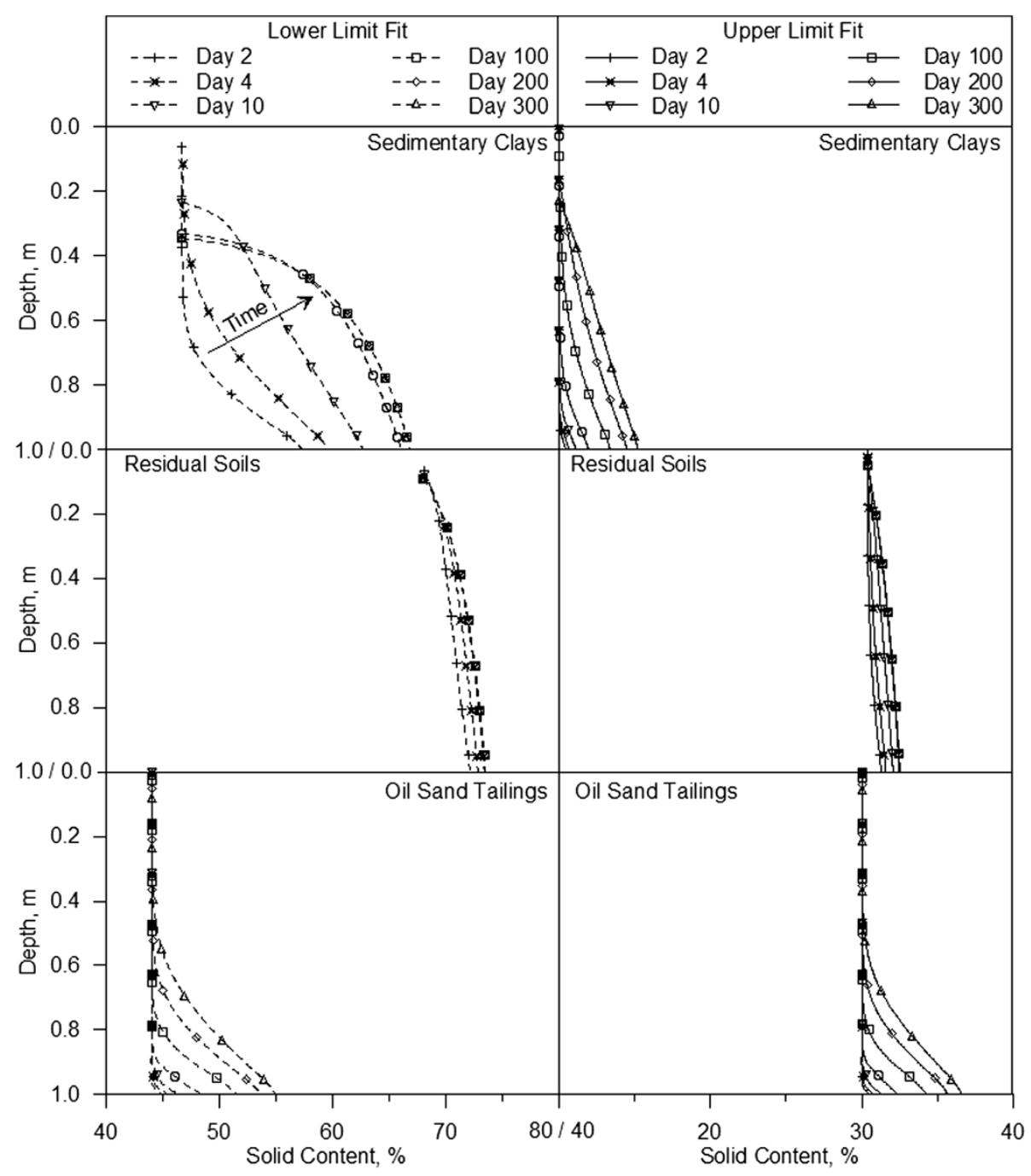

Figure 12 Model prediction results in terms of solids content profiles. 
conditions. The general purpose model can be improved to include heterogamous tailings using a multi-dimensional approach. Results indicated that hydraulic conductivity (Figure 8) along with specific gravity (Table 1) dictated the rate of consolidation with respect to both time and depth, as evident from pore water pressure dissipation (Figure 9) and effective stress development (Figure 10), Likewise, volume compressibility (Figure 7) and initial solids was found to govern the amount of consolidation with respect to both time and depth, as given by void ratio reduction (Figure 11) and solids content increase (Figure 12). The model captured the self-weight consolidation behaviour for a wide range of tailings. The load-deformation based model can be extended to include the sedimentation part of slurry settling thereby incorporating the effect of physiochemical interactions.

\section{Competing interests}

The authors declare that they have no competing interests.

\section{Authors' contributions}

$\mathrm{Ml}$ carried out numerical modelling and drafted the manuscript. SA provided conceptual guidance and polished the manuscript. Both authors read and approved the final manuscript.

\section{Acknowledgements}

The authors acknowledge the financial support provided by the Natural Science and Engineering Research Council of Canada and the computation facilities provided by the University of Regina.

Received: 29 April 2013 Accepted: 15 July 2013

Published: 24 July 2013

\section{References}

Azam S, Chalaturnyk RJ, Scott JD (2005) Geotechnical characterization and sedimentation behavior of laterite slurries, Geotechnical Testing Journal. ASTM 28(6):523-533

Azam S, Jeeravipoolvarn S, Scott JD (2009) Numerical modeling of tailings thickening for improved mine waste management. J Environ Inform 13(2):111-118

Azam S, Li Q (2010) Tailings dam failures: A review of the last one hundred years, Geotechnical News. BiTech Publishers Limited 28(4):50-53

Bartholomeeusen G, Sills GC, Znidarčić D, Van Kesteren W, Merckelbach LM, Pyke R, Carrier WD, Lin H, Penumadu D, Winterwerp H, Masala S, Chan D (2002) Sidere: numerical prediction of large-strain consolidation. Geotechnique 52:639-648

Caldwell JA, Ferguson K, Schiffman RL, van Zyl D (1984) Application of Finite Strain Consolidation Theory for Engineering Design and Environmental Planning of Mine Tailings Impoundments, Sedimentation Consolidation Models - Predictions and Validation, pp 581-606

Cooling DJ (1985) Finite strain consolidation of red mud residue from the alumina refining industry MASc. Thesis. Western Australian Institute of Technology, Perth, Western Australia

Gibson RE, England GL, Hussey MJL (1967) The theory of one-dimensional consolidation of saturated clays. I. Finite non-linear consolidation of thin homogeneous layers. Géotechnique 17(3):261-273

Jeeravipoolvarn S, Chalaturnyk RJ, Scott JD (2009a) Sedimentation-consolidation modeling with an interaction coefficient. Comp Geotech 36:351-361

Jeeravipoolvarn S, Scott JD, Chalaturnyk RJ (2009b) 10 m standpipe tests on oil sands tailings: long-term experimental results and prediction. Can Geotech J $46: 875-888$

Koppla SD (1970) The Consolidation of Soils in Two-Dimensions and with Moving Boundaries. PhD Thesis. The University of Alberta, Edmonton, Canada

Lord ERF, Liu Y (1998) Depositional and geotechnical characteristics of paste produced from oil sands tailings, Proceedings of $5^{\text {th }}$ International Conference on Tailings and Mine Waste. Balkema, Rotterdam, pp 147-157
Matyas EL, Welch DE, Reades DW (1984) Geotechnical parameters and behavior of uranium tailings. Can Geotech J 21:489-504

McNabb A (1960) A mathematical treatment of one-dimensional soil consolidation. Q Appl Math 17(4):337-347

McRoberts EC, Nixon JF (1976) A theory of soil sedimentation. Can Geotech J 13:294-310

Miller WG, Scott JD, Sego DC (2010) Influence of the extraction process on the characteristics of oil sands fine tailings, Journal of Canadian Institute of Mining. Metallurgy Petroleum 1(2):93-112

Mikasa M (1965) The consolidation of soft clay: A new consolidation theory and its application. Japanese Society of Civil Engineers, Civil Engineering in Japan, pp 21-26

Newson T, Dyer T, Adam C, Sharp S (2006) Effect of structure on the geotechnical properties of bauxite residue. J Geotech Geoenviron Eng, ASCE 132(2):143-151

Paul AC, Azam S (2013) Assessment of slurry consolidation using index properties. Int J Geotech Eng 7(1):55-62

Priestley D (2011) Modeling Multidimensional Large Strain Consolidation of Tailings. MSc Thesis. University of British Columbia, British Columbia, Canada

Priestley D, Fredlund M, van Zyl D (2011) Modeling consolidation of tailings impoundment in one and two dimensions. Proceedings, Tailings and Mine Waste 2011, Vancouver, BC, Canada

Roma JR (1976) Geotechnical properties of Florida phosphatic clay, MS Thesis. Massachusetts Institute of Technology, Cambridge, MA

Terzaghi K, Peck RB, Mesri G (1996) Soil Mechanics in Engineering Practice, 3rd edition. John Wiley and Sons, Inc., Hoboken, New Jersey, USA

Townsend FC, MCVay MC (1990) SOA: Large strain consolidation predictions. ASCE J Geotech Eng 116(2):222-243

Somogyi F (1980) Large Strain Consolidation of Fine Grained Slurries. Presented at the Canadian Society for Civil Engineering, Winnipeg, MB

Wesley LD (2010) Fundamentals of Soil Mechanics for Sedimentary and Residual Soils. John Wiley and Sons, Inc., Hoboken, New Jersey, USA

Znidarcic D, Schiffman RL, Pane V, Croce P, Ko HY, Olsen HW (1986) Theory of one-dimensional consolidation of saturated clays: part $\mathrm{V}$, constant rate of deformation testing and analysis. Géotechnique 36(2):227-237

doi:10.1186/2193-2697-2-7

Cite this article as: Ito and Azam: Large-strain consolidation modeling of mine waste tailings. Environmental Systems Research 2013 2:7.

\section{Submit your manuscript to a SpringerOpen ${ }^{\odot}$ journal and benefit from:}

- Convenient online submission

Rigorous peer review

- Immediate publication on acceptance

- Open access: articles freely available online

- High visibility within the field

- Retaining the copyright to your article

Submit your next manuscript at $>$ springeropen.com 